\title{
Paternal Allele of IGF2 Gene Haplotype CTG Is Associated With Fetal and Placental Growth in Japanese
}

\author{
KEN NAGAYA, YOSHIO MAKITA, GENYA TAKETAZU, TOSHIO OKAMOTO, EIKI NAKAMURA, \\ TOKITSUGI HAYASHI, AND KENJI FUJIEDA
}

Department of Pediatrics, Asahikawa Medical College, Asahikawa, Hokkaido 078-8510, Japan

\begin{abstract}
IGF-II associates with feto-placental growth in rodent and human. We determined three tag-single nucleotide polymorphisms (SNPs) to investigate haplotype frequency of $I G F 2$ relative to size at birth in 134 healthy Japanese infants. In addition, a total of 276 healthy infants were investigated to determine whether common genetic variation of $I G F 2$ might contribute to feto-placental growth using haplotype analysis. Further, quantitative methylation analysis of the IGF2/H19 was performed using the MassARRAY Compact system. In the initial study, the frequency of haplotype CTG from the paternal allele in small for date (SFD) infants was significantly higher than that in non-SFD infants $(p=0.03)$. In a second study, the CTG haplotype infants exhibited significantly lower birth length, weight, and placental weight compared with non-CTG infants. Further, the number of infants less than $-1.5 \mathrm{SD}$ (SD) birth weight in CTG haplotype was higher than those in non-CTG infants. There was no significant difference in the methylation status of $H 19 / I G F 2$ in the two haplotypes. In conclusion, inheriting the IGF2 CTG haplotype from a paternal allele results in reduced feto-placental growth, but it is not associated with the methylation status of $I G F 2 / H 19$. (Pediatr Res 66: 135-139, 2009)
\end{abstract}

$\mathrm{N}$ umerous factors have been identified as influencing size at birth. Fetal growth can be determined by maternal, placental, and fetal factors. Although abnormalities of these factors may cause IUGR, it is difficult to clarify the etiology for the majority of IUGR.

Intrauterine hormones and growth factors play an important role for regulation of fetal growth. Of those, the IGF family has been implicated in the pathogenesis of IUGR (1). IGF-I and IGF-II, as well as their receptors, are synthesized in a number of fetal and placental tissues and are involved in autocrine/paracrine stimulation of cellular proliferation and differentiation in development (2). The birth weight of the $I G F 1$ knockout mouse is $60 \%$ of wild type and that of the IGF1 receptor knockout mouse is $75 \%$ of wild type (3). This is consistent with the reduced birth weights seen in human with mutations or deletions in $I G F 1$ (4) and $I G F 1$ receptor genes (5). Further, polymorphisms of the IGFl gene are

Received January 21, 2009; accepted March 12, 2009

Correspondence: Ken Nagaya, M.D., Department of Pediatrics, Asahikawa Medical College, 2-1-1-1 Midorigaoka-higashi, Asahikawa, Hokkaido 078-8510, Japan; e-mail: nagaya5p@asahikawa-med.ac.jp

Supported by KAKENHI (17591137 and 21591307); Grant-in-Aid for Scientific Research (C) by Japan Society for the Promotion of Science (JSPS). related to prenatal and postnatal growth (6). The birth weight of the IGF2 knockout mouse is also 60\% of wild type and their placental weights are $75 \%$ of wild type (7). In rodents, it is clear that IGF-II is associated with fetal growth, especially placental growth (8). In human, IGF2 is located at chromosome $11 \mathrm{p} 15.5$, which contains a cluster of imprinted genes that are crucial in the control of fetal growth. This cluster includes paternally expressed genes (such as IGF2 and KCNQ1OTI) and maternally expressed genes (such as $\mathrm{H} 19$ and $C D K N I C$ ) (9). Studies of several transgenic or knockout mouse models $(3,7,8,10)$, and Beckwith-Wiedemann syndrome (BWS) (11) or Silver-Russell syndrome (SRS) (12) in humans, indicate that this region has a key role in fetal development. However, it is not clear whether common genetic variations of IGF2 contribute to feto-placental growth, the way some studies showed an association between polymorphisms of the $I G F 1$ gene and size at birth $(6,13,14)$. Therefore, we investigated the relation between IGF2 gene polymorphisms and feto-placental growth using haplotype analysis.

\section{MATERIALS AND METHODS}

Subjects. We first investigated haplotype frequency of $I G F 2$ relative to size at birth in 134 pairs of healthy Japanese infants and their mothers in the initial study. Subsequently, a total of 276 infants including 134 infants in initial study were finally investigated for the association between polymorphism of the paternal allele of $I G F 2$ gene and feto-placental growth by haplotype analysis. All infants were born at $\geq 35 \mathrm{wk}$ of gestational age in The Center for Infant and Maternal Health at the Asahikawa Medical Collage or the Mori Obstetrics and Gynecology Hospital in Asahikawa between October 2004 and September 2007. Their mothers did not have any complications including pregnancy-induced hypertension. The birth weight, length, and head circumference and its SDS according to Japanese standards (15) was normally distributed. The gestational age was corrected with a crown-rump length in the early gestation by fetus echography. Small for date (SFD) infant was defined as the infant that SDS of birth weight and birth length were below $-1.5 \mathrm{SD}$.

The study was approved by the local institutional review board (the ethics committees in Asahikawa Medical College), and an informed parental consent was obtained prior studying all cases.

Identification of IGF2 gene polymorphism from the paternal allele. Genomic DNA was extracted from cord and maternal whole blood using standard protocols. The samples from 134 infants in the initial study were analyzed for single nucleotide polymorphisms (SNPs) from a database of Japanese Single Nucleotide Polymorphisms (JSNP: http://snp.ims.utokyo.ac.jp/index_ja.html) by PCR followed by whole length direct sequenc-

Abbreviations: AFD, appropriate for date; HFD, heavy for date; SFD, small for date; SRS, Silver-Russell syndrome 


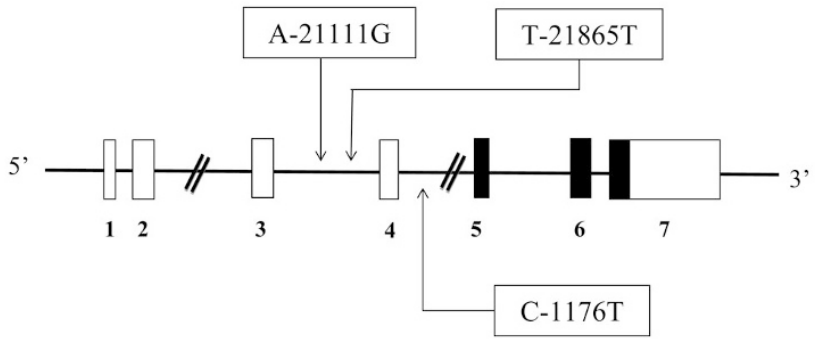

Figure 1. Tag SNPs on IGF2 sellected after linkage disequilibrium study of 48 controls.

Table 1. The patterns guessed as offspring IGF2 paternal haplotype

\begin{tabular}{ccc}
\hline Offspring diplotype & Maternal diplotype & Paternal haplotype \\
\hline AA & AA & A \\
AA & AB & A \\
AB & AA & B \\
AB & AB & Unknown \\
AB & BB & A \\
BB & AB & B \\
BB & BB & B
\end{tabular}

Diplotype: combination of haplotypes.

ing. Thereafter, three tag-SNPs were extracted to identify haplotypes with linkage disequilibrium test by SNPAlyse software (Dynacom, Yokohama, Japan) (Fig. 1): C-1176T (rs1003484), T-21865C (rs3741211), and A-21111G (rs3741206). The selection criteria for tag-SNPs were pairwise correlation with $r^{2}$ and $D^{\prime}>0.8$. Subsequently, total of 276 samples were analyzed for these three tag-SNPs by similar methods.

Genomic DNA was amplified using the following primer sets: for C-1176T, L-GAGGCACATGGATTGGAGTC and R-GGCCTTTCTCATTCCCATTT; for T-21865C, L-CCTCACTGGCCTCGTCAAG and R-CACAAGCTCG GTGGTGACTC; for A-21111G, L-GAACACACAGCTGTCTTCACAAG and R-GACACACAGC TCTGCTTGACG. Target sequences were amplified in a PCR with Takara PCR Amplification Kit (Takara Bio Inc., Japan). PCR amplification was performed using $100 \mathrm{nag}$ of genomic DNA in a $12.5 \mu \mathrm{L}$ volume with $1 \mu \mathrm{L}$ of $2.5 \mathrm{mM}$ dNTPs, $0.625 \mu \mathrm{L}$ of $25 \mathrm{mM} \mathrm{MgCl} 2,1 \mu \mathrm{L}$ of $10 \mathrm{pmol} / \mathrm{L}$ each primer, and $0.5 \mathrm{U} \mathrm{TaqDNA}$ polymerase. For all primer pairs, after heating to $94^{\circ} \mathrm{C}$ for $4 \mathrm{~min}, 35$ cycles were performed at $94^{\circ} \mathrm{C}$ for $30 \mathrm{~s}, 55^{\circ} \mathrm{C}$ for $30 \mathrm{~s}$, and $72^{\circ} \mathrm{C}$ for $30 \mathrm{~s}$ before a final step of $72^{\circ} \mathrm{C}$ for $7 \mathrm{~min}$. PCR products were electrophoreses by the ABI Prism 310 Genetic Analyzer (Applied Biosystems, Foster City, CA) and analyzed using the GeneScan and customized Genotyper software packages (Applied Biosystem).

Haplotype analysis [estimation of maximum likelihood haplotype frequencies and differences in haplotypic distribution between SFD infants and AFD (appropriate for date)/HFD (heavy for date) infants] was carried out using Alrequin software (http://anthropologie.unige.ch/arlequin/methods.html). The haplotype counts were estimated based on EM estimates of haplotype frequency. The permutation test was conducted to confirm differences in haplotypic distribution using SNPAlyze software (Dynacom, Yokohama, Japan, http://www.dynacom.co.jp). Furthermore, because the IGF2 gene is an imprinted gene expressed from the paternal allele, we deduced the haplotype of the paternal allele as a result of a combination of the infant and maternal diplotypes according to Table 1 .

Quantification of CTCF site 6 and H19 DMR methylation by MassAR $\boldsymbol{R A Y}$. Quantitative methylation analysis of the IGF2/H19 was performed using the MassARRAY Compact system (Sequenom, San Diego, CA). This system uses mass spectrometry (MS) for the detection and quantitative analysis of DNA methylation using homogenous MassCLEAVE base-specific cleavage and matrix-assisted laser depsorption/ionization time-of-flight MS (16). Genomic DNA was converted with sodium bisulfite using EZ DNA methylation kit (Zymo Research, San Francisco, CA). Biasulfite-treated DNA was subjected to IGF2/ $H 19$ specific PCR to CpG regions CTCF6 and H19 DMR. The primers were (underlined nucleotides are gene-specific sequences): CTCF6, L-agg aagagagGGTGTTTTAGTTTTATGGATGATGG, R-cagtaatacgactcactatagggagaaggetAAATATCCTATTCCCAAATAACCCC; $H 19$ DMR, L-aggaagagagTTTTTATTAAAGGTTAAGGTGGTGAT, R-cagtaatacgactcactatagggag aaggctAATAACACAAAAAACCCCTTCCTAC). Each reverse primer has a
Table 2. Frequency of offspring IGF2 haplotypes from paternal allele

\begin{tabular}{lcccc}
\hline Haplotypes & $\begin{array}{c}\text { Overall } \\
(n=134)\end{array}$ & $\begin{array}{c}\text { HFD/AFD } \\
(n=105)\end{array}$ & $\begin{array}{c}\text { SFD } \\
(n=29)\end{array}$ & $p$ \\
\hline TTA & $48(35.8)$ & $38(36.2)$ & $10(34.5)$ & NS \\
CCA & $29(21.6)$ & $25(23.8)$ & $4(13.8)$ & NS \\
CTG & $26(19.4)$ & $15(14.3)$ & $11(37.9)$ & 0.03 \\
CTA & $3(2.2)$ & $2(1.9)$ & $1(3.5)$ & - \\
TCA & $1(1.5)$ & $2(1.9)$ & $0(0)$ & - \\
Others & $3(2.1)$ & $3(2.9)$ & $0(0)$ & - \\
Unknown & $23(17.2)$ & $20(19.0)$ & $3(10.3)$ & NS \\
\hline
\end{tabular}

The values are represented as $n(\%) . \%$ indicates haplotype frequency in each groups.

T7-promotor tag for in vitro transcription (5'-cagtaatacgactcactatagggagaaggct- $\left.3^{\prime}\right)$, and the forward primer is tagged with a 10 -mer to balance PCR (5'-aggaagagag- $\left.3^{\prime}\right)$. Amplification of $1 \mu \mathrm{L}$ of bisulfite-treated DNA was performed using HotStar Taq polymerase (Qiagen, Hilden, Germany) in a $5-\mu \mathrm{L}$ reaction volume using PCR primers at a $200 \mathrm{nM}$ final concentration. PCR amplification was performed with the following parameters: $94^{\circ} \mathrm{C}$ for 15 min hot start, followed by denaturing at $94^{\circ} \mathrm{C}$ for $20 \mathrm{~s}$, annealing at $56^{\circ} \mathrm{C}$ for $30 \mathrm{~s}$, extension at $72^{\circ} \mathrm{C}$ for 1 min for 45 cycles, and final incubation at $72^{\circ} \mathrm{C}$ for 3 min. After shrimp alkaline phosphatase treatment, $2 \mu \mathrm{L}$ of the PCR products were used as a template for in vitro transcription and RNase A cleavage for the T-reverse reaction as per the manufacture's instructions (Sequenom). The samples were conditioned and spotted on a 384-pad SpectroCHIP (Sequenom) using a MassARRAY nanodispenser (Samsung, Irvine, CA), followed by spectral acquisition on a MassARRAY Analyzer Compact matrixassisted laser desorption/ionization time-of-flight MS (Sequenom). The resultant methylation was analyzed by the EpiTyper software v1.0 (Sequenom) to generate quantitative results for each $\mathrm{CpG}$ site or an aggregate of multiple $\mathrm{CpG}$ sites.

Statistical analysis. To estimate the significance of differences between the two groups, $t$ test was used. Comparisons of the genotype or allele frequencies between the groups were performed with a $\chi^{2}$ test. The level of significance was set at $p=0.05$.

\section{RESULTS}

In the initial study, the genotype frequencies of $I G F 2$ gene polymorphisms from the paternal allele, as summarized in Table 2, were in Hardy-Weinberg equilibrium. Overall, 48 infants (35.8\%) were haplotype TTA, and haplotype CCA and CTG were $29(21.6 \%)$ and $26(19.4 \%)$, respectively. A total of $76.9 \%$ was occupied in these three haplotypes. Further, there was statistically significant difference in individual paternal IGF2 genotype frequencies observed between SFD infants and AFD/HFD infants evaluated by $\chi^{2}$ analysis. The frequency of paternal haplotype CTG in SFD infants was significantly higher than that in HFD/AFD infants. There was similar distribution for total of 276 infants in subsequent study including 134 infants in initial study. Thus, we investigated feto-placental growth by haplotypes between $I G F 2$ paternal allele haplotype CTG and non-CTG in the subsequent study.

In this study, the characteristics of infants were not significantly different in the two groups (CTG and non-CTG infants). However birth weight, birth length, and placental weight in CTG infants were lower than that in non-CTG infants (Table 3). Although SDS of birth weight and length were not related to the CTG haplotype, the number of infants less than $-1.5 \mathrm{SD}$ birth weight in CTG haplotype was higher than those in non-CTG infants. Moreover, the placental weight corrected for birth head circumference, which was almost maintained stability as gestational age, was significantly lower in case of the CTG haplotype. There were no 
Table 3. Characteristics of the final study population by offspring IGF2 paternal allele haplotypes (mean $\pm S D$ )

\begin{tabular}{|c|c|c|c|}
\hline & Non-CTG (221) & CTG (55) & $p$ \\
\hline Gestational age (wk) & $39.4 \pm 2.9$ & $39.0 \pm 1.3$ & NS \\
\hline Sex (male) & 100 & 23 & \\
\hline \multicolumn{4}{|l|}{ Mother } \\
\hline Height $(\mathrm{cm})$ & $158.5 \pm 5.2$ & $157.6 \pm 5.3$ & NS \\
\hline Birth weight $(\mathrm{g})$ & $3124.9 \pm 437.2$ & $3032.4 \pm 387.5$ & NS \\
\hline Primigravida & 116 & 35 & NS \\
\hline Smoking & 103 & 27 & NS \\
\hline \multicolumn{4}{|l|}{ Father } \\
\hline Height $(\mathrm{cm})$ & $171.9 \pm 5.0$ & $172.3 \pm 5.1$ & NS \\
\hline Birth weight $(\mathrm{g})$ & $3230.5 \pm 500.9$ & $3156.3 \pm 440.5$ & NS \\
\hline Birth weight $(\mathrm{g})$ & $3009.5 \pm 414.4$ & $2850.1 \pm 509.3$ & 0.02 \\
\hline SD score & $-0.2 \pm 1.0$ & $-0.4 \pm 1.0$ & NS \\
\hline No. of SDS $\leq-1.5$ & $23(10.4 \%)$ & $11(20.0 \%)$ & 0.048 \\
\hline Birth length $(\mathrm{cm})$ & $48.3 \pm 2.0$ & $47.6 \pm 3.0$ & 0.04 \\
\hline SD score & $-0.6 \pm 0.9$ & $-0.7 \pm 1.0$ & NS \\
\hline No of SDS $\leq-1.5$ & $36(16.3 \%)$ & $11(20.0 \%)$ & NS \\
\hline Birth head circumference $(\mathrm{cm})$ & $33.6 \pm 1.3$ & $33.5 \pm 1.4$ & NS \\
\hline SD score & $0.0 \pm 0.8$ & $0.0 \pm 0.6$ & NS \\
\hline Placental weight (g) & $582.7 \pm 109.0$ & $542.7 \pm 126.1$ & 0.02 \\
\hline $\begin{array}{l}\text { Placenta/head circumference } \\
(\mathrm{g} / \mathrm{cm})\end{array}$ & $17.2 \pm 2.9$ & $16.1 \pm 3.4$ & 0.03 \\
\hline
\end{tabular}

significant differences in birth head circumference or placenta/ birth weight ratio.

The expression of $I G F 2$ genes is imprinted. Although the $I G F 2$ gene shares an enhancer with the H19 gene, H19 is expressed only from the maternal allele and IGF2 only from the paternally inherited allele (17-19). An imprinted control region (ICR) of paternal specific methylation upstream of $H 19$ appears to be the site of epigenetic imprinting of these genes. The methylation status of ICR acts as a CTCF boundary that blocks the interaction of IGF2 with the enhancer. This enhancerblocking activity is lost when ICR is methylated, thereby allowing expression of $I G F 2$ paternally. Because the previous report of SRS demonstrated the hypomethylation of CTCF site 6 and H19 DMR in H19/IGF2 (12), we assessed the methylation status of CTCF site 6 and H19 DMR, located upstream of H19, by MassARRAY. However, there are no significant differences in CTCF site 6 and IGF2 DMR region between haplotype CTG and non-CTG infants (Fig. 2). Thus, there were no relationship between the methylation status of H19/ IGF2 and paternal haplotypes in this study.

\section{DISCUSSION}

The major finding of this study is that the IGF2 haplotype CTG from the paternal allele (tag SNPs: C-1176T, T-21865C, and A-21111G) is associated with a reduction in placental weight, birth weight, and birth length. However, this haplotype was not associated with the methylation status of CTCF site 6 and H19 DMR in H19/IGF2.

The ratio of IGF-II to the soluble form of IGF2R is related to birth weight (20). The H19 RNA (RNA) has growth suppressing function through inhibiting translation of IGF2 RNA (21). Moreover, recent studies have reported that genetic variation in the $I G F 2$ receptor gene (22) and $H 19$ gene (23) are associated with size at birth in human. These results suggest that IGF-II may also have a role in regulating fetal growth in human.
In the rodent, IGF-II is associated with fetal growth, especially placental growth (8). In mice with homozygous deletion of the IGF2 gene, fetal growth is impaired, and pups have birth weight approximately $60 \%$ those of wild-type animals in both instances (8). Moreover, the mice with homozygous deletion of the IGF2 gene are accompanied by small placental size (10). Our findings also support the notion by demonstrating the relation between $I G F 2$ polymorphism from paternal allele and feto-placental growth in human.

SRS was characterized by severe prenatal and postnatal growth retardation, congenital hemihypertrophy, and characteristic facial features, including triangular shaped face with a broad forehead and pointed, small chin with a wide, thin mouth (12). Several individuals with clinically typical SRS were identified by an epimutation (demethylation) in the telomeric imprinting center region ICR1 of the $11 \mathrm{p} 15$ region. The epigenetic defect was associated with relaxation of imprinting and biallelic expression of $H 19$ and down-regulation of $I G F 2$. These findings provided new insights into the pathogenesis of SRS by strongly suggesting importance of the $11 \mathrm{p} 15 \mathrm{im}-$ printed region. In contrast, we could not demonstrate any relationship between the methylation status of CTCF site 6 and $H 19$ DMR in H19/IGF2 and paternal haplotypes. Thus, our findings could not reveal why IGF2 haplotype CTG from paternal alleles is associated with feto-placental growth. This may suggest that different mechanisms may operate in fetal growth for small normal babies compared with SRS baby.

There are other differentially methylated regions in IGF2/ $H 19$ (H19 promoter, IGF2 DMR2, CTCF site 1-5) and human chromosome $11 \mathrm{p} 15.5$ cluster contains other imprinted gene (KCNQ1OT1, CDKN1C) that control growth and development $(24,25)$. Further, three systems, including DNA methylation, RNA-associated silencing and histone modification, are used to initiate and sustain epigenetic silencing. They interact and stabilize each other. Disruption of one or other of these interacting systems can lead to inappropriate expression or silencing of genes, resulting in "epigenetic diseases" (26). Other modifications of the $I G F 2$ gene except for DNA methylation may operate. Therefore, further research is needed to confirm whether paternal IGF2 haplotype CTG associate with epigenetic modifications.

We measured IGF-I, IGF-II, and IGF binding protein (IGFBP)-3 levels in cord blood in only 142 of 276 infants in both groups (29 of CTG infants and 113 of non-CTG infants). Although these data were only partial, there was no difference in IGF-I, IGF-II, and IGFBP-3 levels in cord blood between haplotypes (data were not shown). However, although we could not examine the expression of genes in placentas, the expression of IGF2 in placenta may decrease in CTG infants. Recently, Constancia et al. (8) demonstrated that a deletion from the $I G F 2$ gene of a transcript from the P0 promoter specifically expressed in the labyrinthine trophoblast of the murine placenta leads to reduced growth of the placenta, followed several days later by fetal growth restriction. Monk et al. identified a human equivalent to the mouse P0 transcript that is paternally expressed in all fetal and placental material except pancreas. Further, they have found the human IGF2-PO transcript start site that has promoter activity (27). Similar to the 

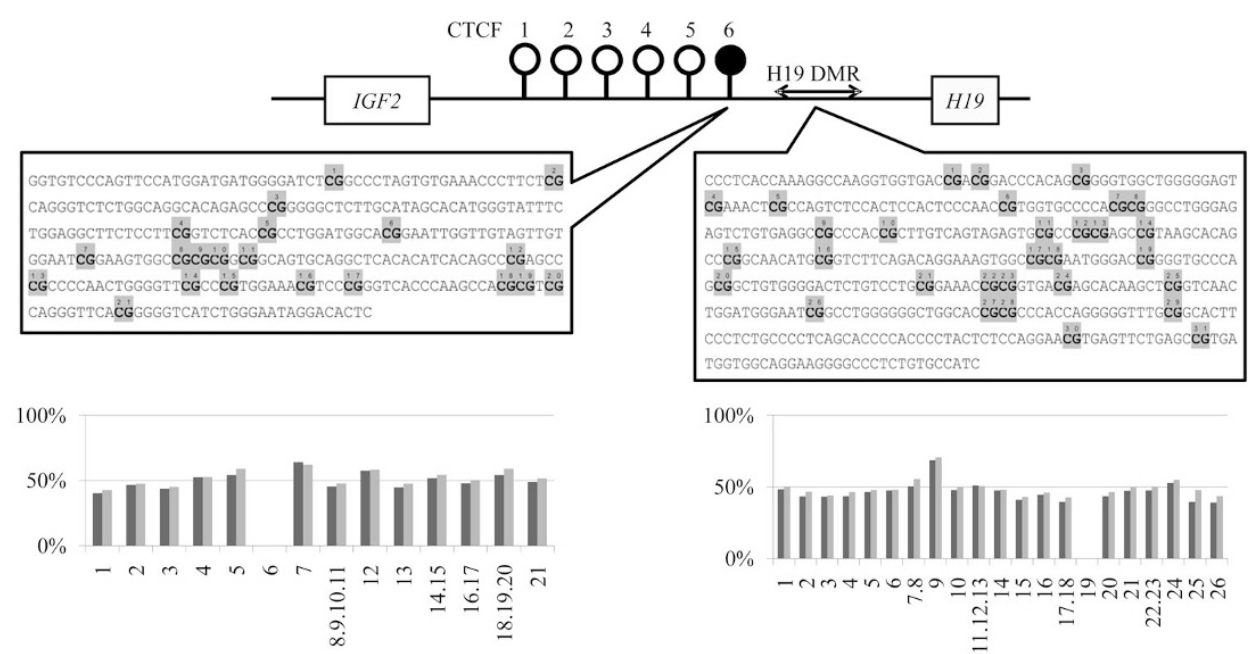

Figure 2. Schematic diagram showing the position of CpG islands (CTCF6, DMR) at IGF2/H19 gene and methylation status of these sites on paternal haplotypes. The numbers on the $X$-axis indicate methylation sites in CTCF6 and H19 DMR regions. The black boxes are CTG infants and the grey boxes are non-CTG infants.

mouse, the human $I G F 2-P 0$ transcript is paternally expressed. However, its expression is not limited to placenta. Similar to the mouse, if placental-specific transcripts in human were identified as the mouse IGF2-PO transcript, the dysfunction or down-regulation of these transcripts may explain our findings that IGF2 haplotype CTG from paternal alleles associate with feto-placental growth with no difference in cord blood IGF-II. Although further research must be investigated the expression of $I G F 2$ in placenta, we could not prepare for placental examination in this study.

In previous human studies, IGF-II levels at birth had no significant relationships with size at birth (20). These associations with growth factor levels at birth in term deliveries may be weakened by the inability to consider gestational stagedependent effects on fetal growth. The ratio of IGF-II to the inhibitory soluble IGF2R was significantly related to birth weight, ponderal index, and placental weight in one study (20). We could not show these associations because we did not measure soluble IGF2R level in cord blood.

For preliminary postnatal growth assessment, we investigated by questionnaires the parents of 215 infants who were 18 mo of age. In Japan, the skilled public health nurses performed accurately the routine examinations for infants' growth and development at key ages $(4,18$, and $36 \mathrm{mo})$ in local communities. We assessed postnatal growth of infants at 18 mo of life at the routine examinations. We received replies from only 87 (15 of CTG infants and 72 of non-CTG infants) parents to the questionnaires. There were no significant differences in body weight in both groups. However, height at 18 mo in CTG infants was significantly shorter than that in non-CTG infants (78.4 \pm 2.7 versus $80.3 \pm 2.8, p=0.02$ ). Moreover, SDS of height and body mass index (BMI) in CTG infants were significantly lower than those in non-CTG infants at 18 mo of age $(-1.1 \pm$ 0.9 versus $-0.4 \pm 0.9, p=0.01,9.2 \pm 2.7$ versus $10.4 \pm 1.1$, 0.004 , respectively). The infants with $I G F 2$ haplotype CTG did not appear to catch up by 18 mo of age. Although our follow-up data were only partial, it suggested that paternal
IGF2 haplotype CTG might be associated with postnatal growth by 18 mo of age. This result is incompatible with the postnatal growth of IGF2 knockout mice (7). However, it could not be concluded that this haplotype associated postnatal growth in human because of low follow-up rate and duration.

Recent research has linked low birth weight with an increased prevalence of hypertension, hypercholesterolemia, and cardiovascular disease later in life (28). Common variants in $I G F 2$ gene could contribute to fetal growth restraint and compensatory postnatal catch-up growth. O'Dell et al. (29) reported that IGF2 ApaI AA genotype was associated with lower mean body weight and body mass index but higher serum IGF-II levels than GG genotype in middle-aged males. Furthermore, relatively higher IGF-II levels were also associated with a reduced risk of gaining weight (30). Sandhu et al. revealed that individuals who developed obesity had lower baseline IGF-II levels. Thus, because it is suggested that IGF-II is associated body size in adulthood, it is important to clarify the association between IGF2 gene haplotype CTG from paternal allele and metabolic disease in later life in future.

\section{REFERENCES}

1. Fowden AL 2003 The insulin-like growth factors and feto-placental growth. Placenta 24:803-812

2. Randhawa R, Cohen P 2005 The role of the insulin-like growth factor system in prenatal growth. Mol Genet Metab 86:84-90

3. Baker J, Lin JP, Robertson EJ, Efstratiadis A 1993 Role of insulin-like growth factors in embryonic and postnatal growth. Cell 75:73-82

4. Woods KA, Camacho Hubner C, Savage MO, Clark AJ 1996 Intrauterine growth retardation and postnatal growth failure associated with deletion of the insulin-like growth factor I gene. N Engl J Med 335:1363-1367

5. Wertheimer E, Lu SP, Backeljauw PF, Davenport ML, Taylor SI 1993 Homozygous deletion of the human insulin receptor gene results in leprechaunism. Nat Genet 5:71-73

6. Arends N, Johnston L, Hokken-Koelega A, Duijn CD, Ridder MD, Savage M, Clark A 2002 Polymorphism in the IGF1 gene: clinical relevance for short children born small for gestational age (SGA). J Clin Endocrinol Metab 87:2720-2724

7. DeChiara TM, Robertson EJ, Efstratiadis A 1990 A growth-deficient phenotype in heterozygous mice carry an insulin-like growth factor II gene disrupted by targeting. Nature 345:78-80 
8. Constancia M, Hemberger M, Hughes J, Dean W, Ferguson-Smith A, Fundele R, Steward F, Kelsey G, Fowden AL, Sibley C, Reik W 2002 Placental-specific IGF2 is a major modulator of placental and fetal growth. Nature 417:945-948

9. Smith AC, Choufani S, Ferreira JC, Weksberg R 2007 Growth regulation, imprinted genes, and chromosome 11p15.5. Pediatr Res 61:43R-47R

10. Efstratiadis A 1998 Genetics of mouse growth. Int J Dev Biol 42:955-976

11. Sparago A, Cerrato F, Vernucci M, Ferrero GB, Silengo MC, Riccio A 2004 Microdeletions in the human H19 DMR result in loss of IGF2 imprinting and Beckwith-Wiedemann syndrome. Nat Genet 36:958-960

12. Giquel C, Rossignol S, Cabrol S, Houang M, Steunou V, Barbu V, Danton F, Thibaud N, Le Merrer M, Burglen L, Bertrand AM, Netchine I, Le Bouc Y 2005 Epimutation of the telomeric imprinting center region on chromosome $11 \mathrm{p} 15$ in Silver-Russell syndrome. Nat Genet 37:1003-1007

13. Vaessen N, Janssen JA, Heutink P, Hofman A, Lamberts SW, Oostra BA, Pols HA, van Duijn CM 2002 Association between genetic variation in the gene for insulinlike growth factor-I and low birthweight. Lancet 359:1036-1037

14. Johnston LB, Dahlgren J, Leger J, Gelander L, Savage MO, Czernichow P, Wikland KA, Clark AJ 2003 Association between insulin-like growth factor I (IGF-I) polymorphisms, circulating IGF-I, and pre- and postnatal growth in two European small for gestational age populations. J Clin Endocrinol Metab 88:4805-4810

15. Nishida H, Sakamoto S, Sakanoue M 1985 New fetal growth curves for Japanese. Acta Paediatr Scand Suppl 319:62-67

16. Ehrich M, Nelson MR, Stanssens P, Zabeau M, Liloglou T, Xinaranous G, Cantor CR, Field JK, van den Boom D 2005 Quantitative high-throughput analysis of DNA methylation patterns by base-specific cleavage and mass spectrometry. Proc Natl Acad Sci USA 102:15785-15790

17. Bell AC, Felsenfeld G 2000 Methylation of a CTCF-dependent boundary controls imprinted expression of the igf2 gene. Nature 405:482-485

18. Hark AT, Schoenherr CJ, Katz DJ, Ingram RS, Levorse JM, Tilghman SM 2000 CTCF mediates methylation-sensitive enhancer-blocking activity at the H19/igf2 locus. Nature 405:486-489

19. Reik W, Murrell A 2000 Genome imprinting: silence across the border. Nature 405:408-409

20. Ong K, Kratzsch J, Kiess W, Costello M, Scott C, Dunger D 2000 Size at birth and cord blood levels of insulin, insulin-like growth factor I (IGF1), IGF2, IGF-binding protein-1 (IGFBP-1), IGFBP-3, and the soluble IGF2/,mannose-6-phosphate receptor in term human infants. J Clin Endocrinol Metab 85:4266-4269

21. Li YM, Franklin G, Cui HM, Svensson K, He XB, Adam G, Ohlsson R, Pfeifer S 1998 The H19 transcript is associated with polysomes and may regulate IGF2 expression in trans. J Biol Chem 273:28247-28252

22. Petry CJ, Ong KK, Wingate DL, Brown J, Scott CD, Jones EY, Pembrey ME, Dunger DB; Alspac Study Team 2005 Genetic variation in the type 2 insulin-like growth factor receptor gene and disparity in childhood height. Growth Horm IGF Res 15:363-368

23. Petry CJ, Ong KK, Barratt BJ, Wingate D, Cordell HJ, Ring SM, Pembrey ME, Reik W, Todd JA, Dunger DB; ALSPAC Study Team 2005 Common polymorphism in H19 associated with birth weight and cord blood IGF-II levels in humans. BMC Genet 6:22

24. Abu-Amero SN, Ali Z, Bennett P, Vaughan JI, Moore GE 1998 Expression of the insulin-like growth factors and their receptors in term placentas: a comparison between normal and IUGR birth. Mol Reprod Dev 49:229-235

25. Obermann C, Meyer E, Prager S, Tomiuk J, Wollmann HA, Eggermann T 2004 Searching for genomic variants in IGF2 and CDKN1C in Silver-Russell syndrome patients. Mol Genet Metab 82:246-250

26. Egger G, Liang G, Aparicio A, Jones PA 2004 Epigenetics in human disease and prospects for epigenetic therapy. Nature 429:457-463

27. Monk D, Sanches R, Arnaud P, Apostolidou S, Hills FA, Abu-Amero S, Murrell A Friess H, Reik W, Stanier P, Constancia M, Moore GE 2006 Imprinting of IGF2 Po transcript and novel alternatively splices INS-IGF2 isoforms show differences between mouse and human. Hum Mol Genet 15:1259-1269

28. Barker DJ 2007 The origins of the developmental origins theory. J Intern Med 261:412-417

29. O’Dell SD, Miller GJ, Cooper JA, Hindmarsh PC, Pringle PJ, Ford H, Humphries SE, Day IN 1997 ApaI polymorphism in insulin-like growth factor II (IGF2) gene and weight in middle-aged males. Int J Obes Relat Metab Disord 21:822-825

30. Sandhu MS, Gibson JM, Heald AH, Dunger DB, Wareham NJ 2003 Low circulating IGF2 concentrations predict weight gain and obesity in human Diabetes 52:1403-1408 